\title{
Glucagon-like peptide-1 attenuates advanced oxidation protein product-mediated damage in islet microvascular endothelial cells partly through the RAGE pathway
}

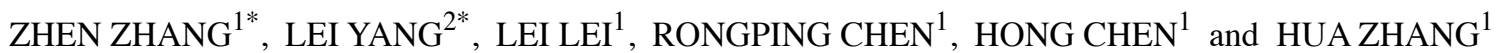 \\ Departments of ${ }^{1}$ Endocrinology and ${ }^{2}$ Nephrology, ZhuJiang Hospital of \\ Southern Medical University, Guangzhou, Guangdong 510282, P.R. China
}

Received August 8, 2015; Accepted August 2, 2016

DOI: $10.3892 / \mathrm{ijmm} .2016 .2711$

\begin{abstract}
Advanced oxidation protein products (AOPPs) are knownt to play a role in the pathogenesis of diseases and related complications. However, whether AOPPs affect the survival of islet microvascular endothelial cells (IMECs) has not been reported to date, at least to the best of our knowledge. In this study, we aimed to investigate the mechanisms underlying AOPP-mediated damage in IMECs and the protective role of glucagon-like peptide-1 (GLP-1), which has been suggested to exert beneficial effects on the cardiovascular system. IMECs were treated with AOPPs $(0-200 \mu \mathrm{g} / \mathrm{ml})$ for $0-72 \mathrm{~h}$ in the presence or absence of GLP-1 (100 nmol/l). Apoptosis, cell viability and reactive oxygen species (ROS) production were examined, the expression levels of p53, Bax, receptor for advanced glycation end-products (RAGE) and $\mathrm{NAD}(\mathrm{P}) \mathrm{H}$ oxidase subunit were determined, and the activity of NAD(P)H oxidase, caspase-9 and caspase- 3 was also determined. The results revealed that AOPPs increased the expression of RAGE, p47 ${ }^{\text {phox }}$ and $\mathrm{p} 22^{\text {phox }}$; induced NAD $(\mathrm{P}) \mathrm{H}$ oxidase-dependent ROS generation, increased p53 and Bax expression, enhanced the activity of caspase-9 and caspase-3, and induced cell apoptosis. Treatment with GLP-1 decreased the expression of RAGE, inhibited $\mathrm{NAD}(\mathrm{P}) \mathrm{H}$ oxidase activity, decreased cell apoptosis and increased cell viability. On the whole, our findings indicate that AOPPs induce the apoptosis of IMECs via the RAGE-NAD(P) $\mathrm{H}$ oxidase-dependent pathway and that treatment with GLP-1 effectively reverses these detrimental effects by decreasing AOPP-induced RAGE expression and restoring the redox
\end{abstract}

Correspondence to: Professor Hong Chen or Professor Hua Zhang, Department of Endocrinology, ZhuJiang Hospital of Southern Medical University, Guangzhou, Guangdong 510282, P.R. China

E-mail: chenhong82330@163.com

E-mail: zhanghua82335@163.com

*Contributed equally

Key words: advanced oxidation protein products, glucagon like peptide-1, islet microvascular endothelial cells, receptor for advanced glycation end-products, NAD(P)H oxidase, apoptosis balance. Our data may indicate that GLP-1 may prove to be beneficial in attenuating the progression of diabetes mellitus.

\section{Introduction}

Numerous clinical studies have demonstrated that diabetes is associated with the chronically elevated production of reactive oxygen species (ROS), which exceeds the antioxidant capacity of the tissue, resulting in oxidative stress, the generation and accumulation of deleterious oxidatively modified products, and tissue injury (1-3). Advanced oxidation protein products (AOPPs) are the dityrosine-containing and crosslinking protein products formed during oxidative stress by the combined reactions of plasma proteins with chlorinated oxidants and have been considered to be markers of oxidant-mediated protein damage (4). Their accumulation has been demonstrated in subjects with obesity and metabolic syndrome, and in diabetic patients with or without vascular complications (5-8).

A number of studies have shown that in addition to being products formed by chronic oxidative stress, AOPPs can also trigger oxidative stress and further stimulate ROS generation in a variety of cells through NADPH oxidases (9-11). An increase in the concentration of plasma AOPPs found in diabetic patients, has been shown to deteriorate the urinary excretion of albumin in both normal rats and rats with streptozotocin-induced diabetes $(12,13)$. As the advanced glycation end-products (AGEs), AOPPs play a pathogenic role via the receptor for AGEs (RAGE) in endothelial cells and induce vascular endothelial dysfunction and accelerate atherosclerosis by elevating the level of oxidative stress and inducing the overexpression of inflammatory factors (14-16). It is widely accepted that pancreatic microvascular endothelial dysfunction and subsequent islet ischemia may be the main cause for the initial dysfunction and apoptosis of $\beta$-cells in type 2 diabetes (17). The apoptosis of islet microvascular endothelial cells (IMECs) likely plays an important role in the pathogenesis of diabetes (18). However, whether AOPPs affect the survival of IMECs and the mechanisms involved have not been reported to date, at least to the best of our knowledge.

Glucagon-like peptide-1 (GLP-1), a brain-gut insulinotropic peptide secreted by intestinal $\mathrm{L}$ cells in response to food ingestion, has been proposed as a prospective target for the clinical treatment of type 2 diabetes (19). In addition to its important 
role in regulating glucose homeostasis, GLP-1 has also been suggested to exert beneficial effects on the cardiovascular system, such as improving blood pressure, vascular tone and myocardial function (20). Recent studies have demonstrated that GLP-1 attenuates the AGE-induced ROS generation in many cell cultures; the protective effect of GLP-1 on oxidative stress is mainly related to its ability to downregulate the mRNA expression of RAGE (21-23). The addition of GLP-1 to a culture medium of AGEs has been shown to restore the redox balance, attenuate AGE-induced RAGE expression and protect $\beta$-cells from the detrimental effects of AGEs (21). However, it remains unknown whether GLP-1 can ameliorate the detrimental effects of AOPPs on IMECs.

Therefore, the present study was conducted to investigate the pathobiological effects of AOPPs on the cellular functions of cultured IMECs and the potential mechanisms responsible for these effects. Additionally, this study aimed to identify the potential protective pathways that are triggered by GLP-1 to counteract AOPP-mediated damage in IMECs.

\section{Materials and methods}

Chemicals and reagents. All reagents for cell culture, GLP-1-(736) amide, Hoechst 33258 and apocynin (NADPH oxidase inhibitor) were purchased from Sigma (St. Louis, MO, USA). The Annexin V-FITC/propidium iodide (PI) apoptosis detection kit was purchased from Invitrogen (Carlsbad, CA, USA). The cell counting kit-8 (CCK-8), ROS and superoxide anion assay kits were purchased from the Beyotime Institute of Biotechnology (Jiangsu, China). Rabbit anti-p47 phox (SC-14015), rabbit anti-p22 ${ }^{\text {phox }}$ (SC-20781), $\beta$-actin (SC-47778), and primary antibodies against RAGE (SC-5563), p53 (SC-126), Bax (SC-23959) and exendin(9-39) (SC-364387), the antagonist for receptor of GLP-1 (GLP-1R), were all purchased from Santa Cruz Biotechnology, Inc. (Delaware, CA, USA). The caspase- 3 and caspase- 9 activity assay kits were obtained from BD Biosciences (Franklin Lakes, NJ, USA).

AOPP preparation. AOPP-rat serum albumin (AOPP-RSA) was prepared as previously described $(12,16,24)$. Briefly, RSA was exposed to $200 \mathrm{mmol} / 1$ of $\mathrm{HOCl}$ for $30 \mathrm{~min}$ and dialyzed against phosphate-buffered saline (PBS) to remove free $\mathrm{HOCl}$ overnight. The AOPP preparation consisted of passing through a Detoxi-Gel column to remove any contaminated endotoxins. Endotoxin levels during the preparation were determined with an amebocyte lysate assay kit and were found to be below $0.025 \mathrm{EU} / \mathrm{ml}$. The content of AOPPs in the preparation was determined as described previously (12). The content of AOPPs was $72.4 \pm 9.8 \mathrm{nmol} / \mathrm{mg}$ protein in the prepared AOPP-RSA and $0.2 \pm 0.02 \mathrm{nmol} / \mathrm{mg}$ protein in the native RSA.

Isolation and purification of IMECs and cell treatment. All animal experiments were approved by the Committee on Animal Experimentation of Southern Medical University, Guangzhou, China and performed in compliance with the university's Guidelines for the Care and Use of Laboratory Animals. Rat islets were isolated from Wistar rats and purified using a previously described standard method (25). Briefly, we used a modified method of collagenase digestion and Ficoll density gradient separation for the isolation and digestion of islets from rats. The islets were stained with DTZ and typan blue; the concentration of the cells was adjusted to $500 \mathrm{IU} / \mathrm{ml}$. The cells were then resuspended in DMEM medium containing 20\% fetal calf serum, $100 \mu \mathrm{g} / \mathrm{ml}$ penicillin/streptomycin and $2 \mathrm{mmol} / \mathrm{l} \mathrm{L}$-glutamine, followed by culture in a $2 \%$ gelatin-coated T25 flask at $37^{\circ} \mathrm{C}$. After a 5-day culture, the IMECs and fibroblasts grew out from adherent islets, and the purification for IMECs was carried out using UEA-1-coated Dynabeads as previously described by Lou et al (26). The final purified rat IMECs were cultured in DMEM containing 20\% FCS, $100 \mu \mathrm{g} / \mathrm{ml}$ penicillin/streptomycin, $2 \mathrm{mmol} / \mathrm{l} \mathrm{L-glutamine,} 4 \mathrm{U} / \mathrm{ml}$ insulin, $40 \mathrm{U} / \mathrm{ml}$ heparin and $100 \mu \mathrm{g} / \mathrm{ml}$ endothelial growth supplement and then seeded in a gelatin-coated T25 flask. The cells were cultured at $37^{\circ} \mathrm{C}$ in a $5 \% \mathrm{CO}_{2}$ incubator. The IMECs were firstly treated with RSA $(200 \mu \mathrm{g} / \mathrm{ml}), 0,50,100$ and $200 \mu \mathrm{g} / \mathrm{ml}$ AOPPs and $200 \mu \mathrm{g} /$ $\mathrm{ml}$ AOPPs together with apocynin $(10 \mu \mathrm{mol} / \mathrm{l})$ for $0-72 \mathrm{~h}$ to investigate the dose and time-effect association of AOPPs on the apoptosis of the cells. Then, in order to investigate the protective effect of GLP-1 against the apoptosis of IMECs, the cells were divided into the negative control group (200 $\mu \mathrm{g} / \mathrm{ml} \mathrm{RSA})$, AOPPs $200 \mu \mathrm{g} / \mathrm{ml}$ group, AOPPs $200 \mu \mathrm{g} / \mathrm{ml}+100 \mathrm{nmol} / 1 \mathrm{GLP}-1$ group and AOPPs $200 \mu \mathrm{g} / \mathrm{ml}+100 \mathrm{nmol} / 1 \mathrm{GLP}-1+100 \mu \mathrm{mol} / 1$ exendin(9-39) group [added AOPP-RSA and GLP-1 after preprocessing by exendin(9-39) for $2 \mathrm{~h}$ ].

Hoechst 33258 staining for apoptosis. The apoptosis of the IMECs was identified under a fluorescence microscope (Olympus BX51; Olympus, Tokyo, Japan) after staining with Hoechst 33258 at a dilution of 1:200 (1 mg/ml stock solution) for $5 \mathrm{~min}$ in the dark. At least 1,000 cells were counted for each experimental condition. The cells treated as indicated were fixed with $4 \%$ paraformaldehyde in PBS, rinsed with PBS, and permeabilized by $0.1 \%$ Triton X-100 for FITC end-labeling of the fragmented DNA of the apoptotic IMECs.

Determination of apoptotic cells by Annexin V-FITC/PI staining. The cells were trypsinized and resuspended at a concentration of $1 \times 10^{6}$ cells $/ \mathrm{ml}$ in diluted binding buffer and were then labeled with Annexin V and PI and examined using the Annexin V-FITC apoptosis detection kit according to the manufacturer's instructions. Flow cytometric analysis was performed with the excitation at $488 \mathrm{~nm}$ as soon as possible.

CCK-8 assay for cell viability. The treated IMECs were cultured in Corning 96-well flat-bottomed microtiter plates. A total of $10 \mu \mathrm{l}$ of CCK- 8 was then added followed by incubation in a high humidity environment at $37^{\circ} \mathrm{C}$ and $5 \% \mathrm{CO}_{2}$ for $1 \mathrm{~h}$, and the optical difference (OD) was read at $460 \mathrm{~nm}$ with a microplate reader (BIO-RAD689; Bio-Rad, Hercules, CA, USA). The OD value represents the proliferative activity.

Assay for measuring intracellular ROS levels. Intracellular ROS generation was measured using the fluorescent probe, dihydroethidium (DHE). Intracellular DHE is oxidized to ethidium, which binds DNA and stains nuclei bright fluorescent red. The IMECs treated in the 24-well plates were incubated with a fresh working solution containing $5 \mathrm{mM}$ DHE in PBS for $30 \mathrm{~min}$ at $37^{\circ} \mathrm{C}$. After chilling on ice, the cultures were washed twice with ice-cold PBS and then visualized using a fluorescence microscope (Olympus BX51; Olympus). The 
total red fluorescence intensities were quantified using image analysis software from NIH.

Estimation of NADPH oxidase activity and the expression of NADPHoxidase subunits. NADPHoxidase activity was assessed by measuring superoxide production. NADPH-dependent $\mathrm{O}_{2}{ }^{-}$ production by homogenates from cultured IMECs was assessed by lucigenin-enhanced chemiluminescence as previously described (27). The chemiluminescence value was recorded every minute for $30 \mathrm{~min}$. The readings for each of the last $5 \mathrm{~min}$ were averaged and expressed as counts per second.

The expression of NADPH oxidase subunits in the membrane was analyzed by western blot analysis as previously described (28). Briefly, membrane proteins were extracted using a ProteoExtract kit according to the manufacturer's instructions. Proteins $(40 \mu \mathrm{g})$ were loaded per lane and electrotransferred onto PVDF membranes by semi-dry transfer. The PVDF membranes were then blocked in 5\% non-fat milk in TBS-Tween-20 for $1 \mathrm{~h}$ at room temperature and incubated overnight at $4^{\circ} \mathrm{C}$ with the primary antibodies, anti-p47 $7^{\text {phox }}$ and anti-p22 $2^{\text {phox }}$ (dilution 1:2,000). Afterwards, the membranes were washed 3 times and incubated for $1 \mathrm{~h}$ at room temperature with appropriate HRP-linked secondary antibodies (dilution 1:2,000; A0208; Beyotime Institute of Biotechnology). The relative protein levels were determined by densitometry using Total Lab 2.0 software.

Measurement of caspase-3 and caspase-9 activity. Caspase-3 and caspase- 9 activity was measured using respective kits according to the manufacturer's instructions. The cells were washed twice with PBS and pelleted via centrifugation. Cell pellets were then resuspended with iced lysis buffer for $10 \mathrm{~min}$. Following centrifugation, cell extracts were transferred to fresh tubes. Specific substrates for caspase-3 or caspase- 9 were added, and the tubes were incubated at $37^{\circ} \mathrm{C}$ overnight. The activity of caspase- 3 and caspase- 9 was assessed by calculating the ratio at OD $405 \mathrm{~nm}$ of the treated cells to the untreated cells.

Western blot analysis for p53, Bax and RAGE. The treated cells were collected, and proteins were isolated as previously described (28). The nuclear and cytosolic proteins were extracted using the cytosolic and nuclear extraction kit according to the manufacturer's instructions (P0028; Beyotime Institute of Biotechnology). First, $40 \mu \mathrm{g}$ protein were electrophoresed on $10 \%$ sodium dodecyl sulfate-polyacrylamide gel electrophoresis (SDS-PAGE) gels and transferred onto PVDF membranes. After blocking with $5 \%(\mathrm{w} / \mathrm{v})$ non-fat milk and washing with Tris-buffered saline-Tween-20 solution, the membranes were incubated with $\beta$-actin (1:400), p53 (1:1,000), Bax (1:300), and RAGE (1:1,000) antibodies. After washing, the blots were incubated with an appropriate HRP-linked secondary antibody (dilution 1:2,000). The relative protein levels were determined by densitometry using Total Lab 2.0 software.

Statistical analysis. All experiments were carried out in triplicate. Continuous variables and data are expressed as the means \pm SD. The data were compared using one-way analysis of variance (ANOVA). Pairwise comparisons were evaluated by the Student-Newman-Keuls test. A two-tailed P-value $<0.05$ was considered to indicate a statistically significant difference. Statistical analyses were conducted using SPSS 13.0 software.

\section{Results}

AOPPs increases the apoptosis of cultured IMECs. To determine whether AOPP accumulation induces IMEC apoptosis, the cells were exposed to the AOPPs at various concentrations $(0-200 \mu \mathrm{g} / \mathrm{ml})$ for $0-72 \mathrm{~h}$. We quantified the rates of cell apoptosis using Annexin V-FITC/PI double staining. The rate of apoptosis was significantly increased in the IMECs exposed to the AOPPs than those exposed to the RSA control. The apoptotic rate in the cells exposed to 100 or $200 \mu \mathrm{g} / \mathrm{ml}$ AOPPs was higher than in those exposed to $50 \mu \mathrm{g} / \mathrm{ml}$ AOPPs, with no significant difference observed between the cells treated withy 100 and $200 \mu \mathrm{g} / \mathrm{ml}$ AOPPs. Treatment with apocynin significantly protected the IMECs from AOPP-induced apoptosis, indicating that the apoptotic processes are dependent on the activation of NADPH oxidase (Fig. 1A). We found that AOPPs $(200 \mu \mathrm{g} / \mathrm{ml})$ induced the apoptosis of IMECs in a time-dependent manner; the apoptotic rate of the cells exposed to the AOPPs for $48 \mathrm{~h}$ was significantly higher than that of the cells exposed for 0,12 and $24 \mathrm{~h}$; however, there was no significant difference when compared to the cells exposed to the AOPPS for $72 \mathrm{~h}$ (Fig. 1B).

Decrease in cell viability induced by AOPPs. Cell viability was measured using the CCK- 8 assay. The results revealed that AOPPs had a significant effect on the viability of the IMECs. A significant decrease in viability was observed in the cells incubated with various concentrations of AOPPs compared with those incubated with RSA only ( $<<0.05$; Fig. 1C). Treatment with apocynin significantly protected the IMECs from the AOPPs-induced decrease in cell viability. We also found that there was a time-dependent effect of AOPPs on the viability of the IMECs; the viability in the group of cells incubated for $48 \mathrm{~h}$ was notably decreased compared with that of the cells incubated for 0,12 and $24 \mathrm{~h}$; however, there was no significant difference when compared to the cells exposed to the AOPPS for (Fig. 1D).

AOPPs induce NADPH oxidase-dependent ROS production in IMECs. To examine the effect of AOPPs on intracellular ROS production, the fluorescence intensity of the intracellular fluorescent probe, DHE, was evaluated. ROS production was significantly increased in the cells exposed to the AOPPs in a dose-dependent manner compared with those exposed to RSA only (Fig. 2A). However, ROS production was completely suppressed by the NADPH oxidase inhibitor, apocynin. These data indicate that NADPH oxidase plays a central role in AOPP-induced ROS generation.

The effect of AOPPs on NADPH oxidase activity was further estimated by measuring NADPH-dependent superoxide production. $\mathrm{O}_{2}^{-}$production derived from $\mathrm{NADPH}$ was significantly enhanced in the AOPP-exposed IMECs compared with the cells incubated with RSA only (Fig. 2B). Furthermore, AOPP-induced $\mathrm{O}_{2}{ }^{-}$generation was almost completely blocked by treatment with apocynin (Fig. 2B).

The increased expression of NADPH oxidase subunits may be necessary for NADPH oxidase sustained activity. We then examined the effect of AOPPs on the expression of NADPH oxidase subunits by western blot analysis. Compared with the RSA-exposed control cells, the expression levels of the essential subunits of NADPH oxidase, $\mathrm{p} 47^{\text {phox }}$ and $\mathrm{p} 22^{\text {phox }}$, in the IMECs were significantly upregulated following exposure 
A

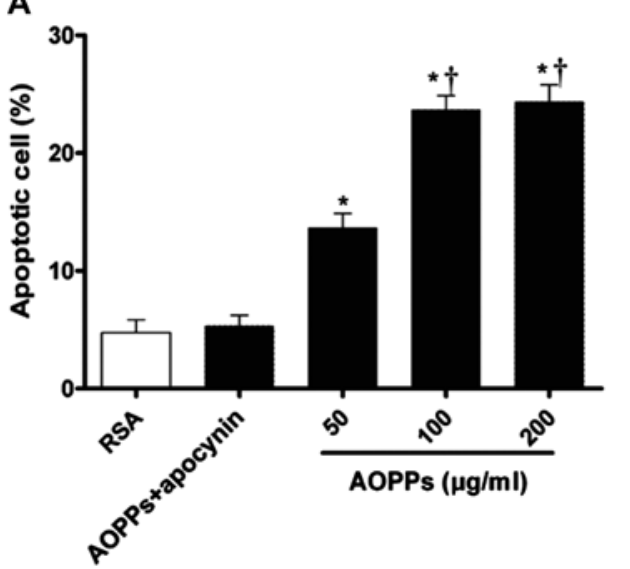

C

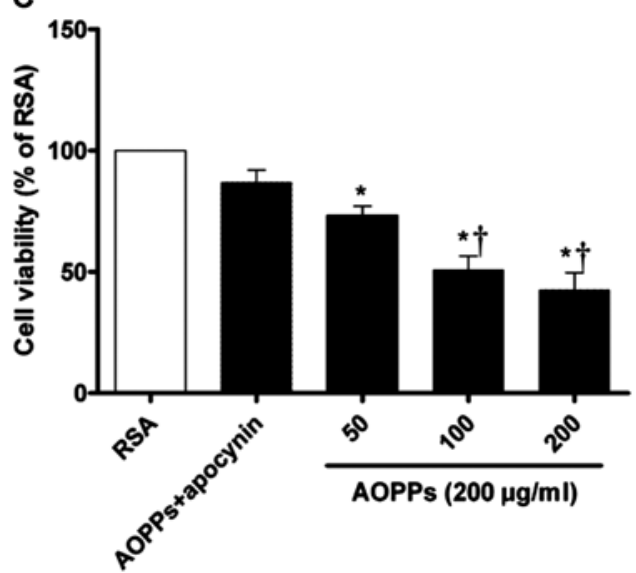

B

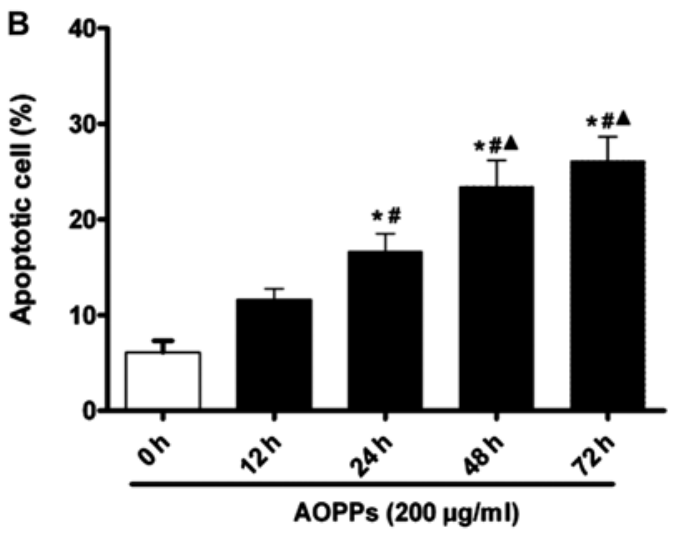

D

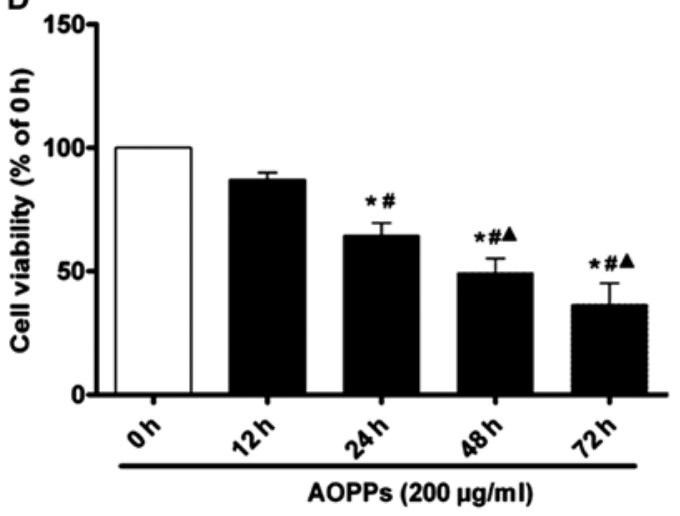

Figure 1. Accumulation of advanced oxidation protein products (AOPPs) induces an increase in apoptosis and a decrease in cell viability in a concentrationdependent manner in islet microvascular endothelial cells (IMECs). (A and B) Apoptosis of rat IEMCs exposed to AOPP-rat serum albumin (RSA) (0-200 $\mu \mathrm{g} /$ $\mathrm{ml}$ ) for 0-72 $\mathrm{h}$ was determined by Annexin V-FITC/propidium iodide (PI) double staining and analyzed quantitatively by flow cytometry. (C and D) Cell viability induced by exposure to AOPP-RSA $(0-200 \mu \mathrm{g} / \mathrm{ml})$ for 0-72 $\mathrm{h}$ in IMECs was measured by cell counting kit-8 assay. Data are expressed as the means \pm SD of 3 independent experiments. " $\mathrm{p}<0.05$ compared with the RSA, or the AOPPs + apocynin (NADPH oxidase inhibitor) group and the $0 \mathrm{~h}$ group; ${ }^{\dagger} \mathrm{p}<0.05$ compared with the AOPP $(50 \mu \mathrm{g} / \mathrm{ml})$-exposed group; ${ }^{\#} \mathrm{p}<0.05$ compared with group exposed to AOPPs for $12 \mathrm{~h} ;{ }^{\wedge} \mathrm{p}<0.05$ compared with the group exposed to AOPPs for $24 \mathrm{~h}$.

to the AOPPs (Fig. 2C). However, treatment with apocynin reversed these effects (Fig. 2C).

RAGE-mediated activation of the p53, Bax and caspase-3 pathways. The Bcl-2 family regulates cell growth and cell apoptosis in many types of models $(9,33)$. The increased expression of p53 has been shown to mediate apoptosis through Bax expression in response to a number of stress signals. Thus, to examine the potential pathways involved in AOPPs-induced apoptosis, we examined the abundance of p53 and Bax proteins by western blot analysis. The AOPP challenge increased p53 expression in the cultured IMECs. The expression of the pro-apoptotic protein, Bax, was also significantly increased compared with that of cells exposed to RSA only (Fig. 3A and B).

To further elucidate the influence of AOPPs on cell apoptosis, the activity of caspase- 3 and caspase- 9 was measured as described in the Materials and methods. As shown in Fig. 3C and D, the activity of caspase-3 and caspase-9 was increased significantly in the cells exposed to the AOPPs when compared with those exposed to RSA only $(\mathrm{p}<0.05)$.

As AOPPs have been shown to signal via RAGE and vascular endothelial cells are known to express RAGE (9), we examined the effects of AOPPs on the expression of RAGE. The AOPP challenge increased RAGE expression in the cultured IMECs in a dose-dependent manner compared to the cells exposed to RSA only ( $<<0.05$; Fig. 5D). These results demonstrated that AOPP-induced apoptosis is mainly associated with the increased activity of caspase- 3 and caspase- 9 , involved in the RAGE-mediated p53/Bax pathway.

Effects of GLP-1 on AOPP-induced apoptosis and cell viability in IMECs. To determine whether GLP-1 treatment alleviates the apoptosis induced by AOPPs, the cells were treated with AOPPs $(200 \mu \mathrm{g} / \mathrm{ml})$ for $48 \mathrm{~h}$ in the presence or absence of GLP-1 (100 nmol/1). The number of Hoechst-positive cells in the cells exposed to the AOPPs was significantly decreased in the presence of GLP-1 compared with the cells exposed to the AOPPS and not treated with GLP-1 (Fig. 4A). The results from Annexin V-FITC/PI double staining revealed that a significantly lower apoptotic rate was observed after the addition of GLP-1 to the culture medium (Fig. 4B). We also evaluated the effects of GLP-1 (100 nmol/l) on the viability of IMECs exposed to AOPPs. The IMECs exposed to the AOPPs exhibited a significant decrease in viability compared with those exposed to RSA only ( $<<0.05$; Fig. 4C). Following co-incubation with GLP-1, cell viability was significantly increased $(\mathrm{p}<0.05)$. However, 
A
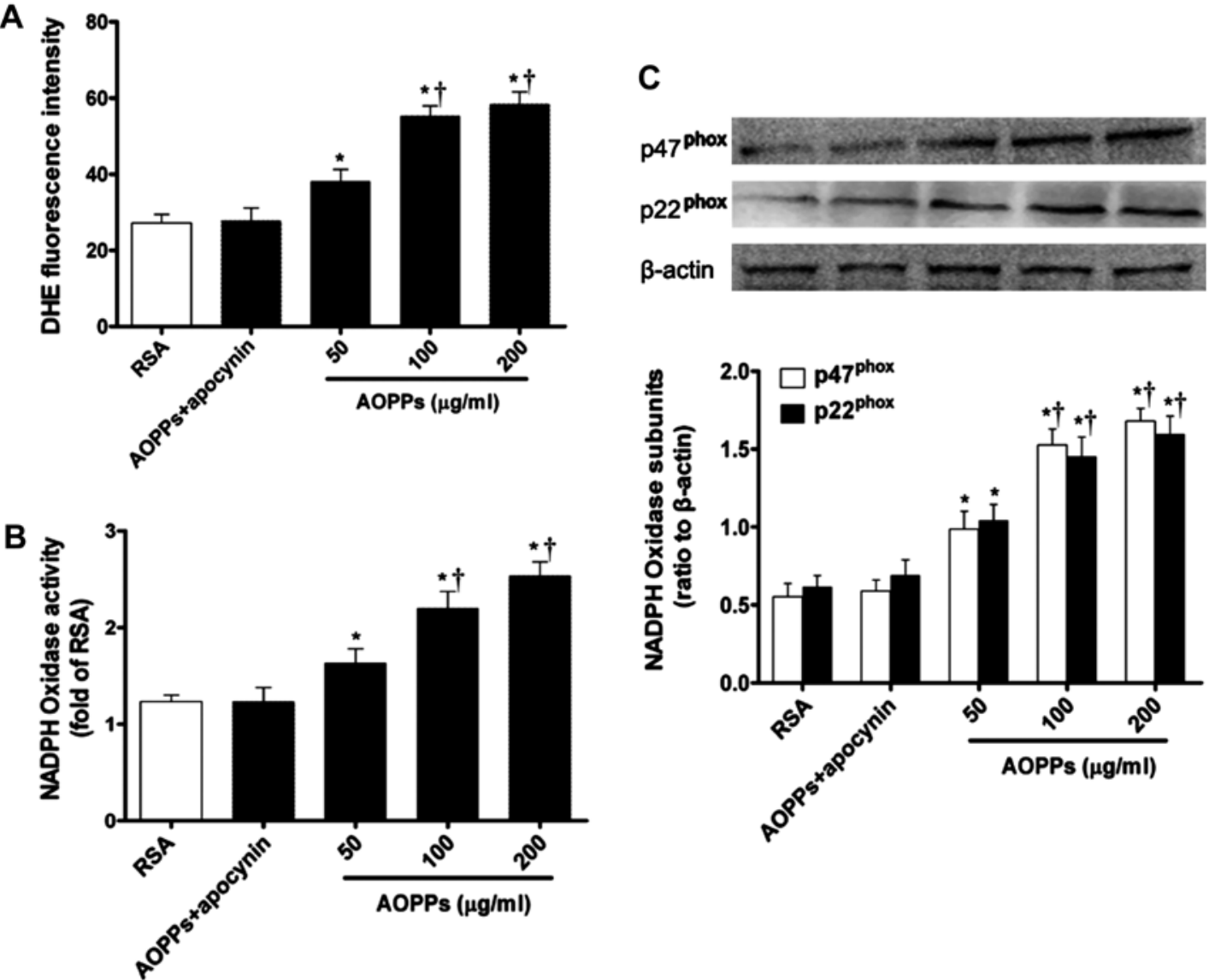

Figure 2. Effect of advanced oxidation protein products (AOPPs) on reactive oxygen species (ROS) generation, NADPH oxidase activity and the expression of NADPH oxidase subunits in cultured IMECs. (A) ROS was measured using the fluorescent probe, dihydroethidium (DHE), in IMECs exposed to AOPPs $(0-200 \mu \mathrm{g} / \mathrm{ml})$ for $48 \mathrm{~h}$. (B) NADPH oxidase activity was estimated by measuring NADPH-dependent $\mathrm{O}_{2}^{-}$production using lucigenin enhanced chemiluminescence method in homogenates from cultured IMECs. (C) Expression of NADPH oxidase subunits, p47 phox and p22 $2^{\text {phox }}$, in the membrane and cytosolic fraction were examined by western blot analysis. Values are the means \pm SD from at least 3 independent experiments. ${ }^{*} \mathrm{p}<0.05$ compared with the rat serum albumin (RSA) or the AOPPs + apocynin group; ${ }^{\dagger} \mathrm{p}<0.05$ compared with the AOPPs $(50 \mu \mathrm{g} / \mathrm{ml})$-exposed group.

the protective effects of GLP-1 on IMECs were blocked by treatment with exendin(9-39), an antagonist for GLP-1R. These data demonstrated that GLP-1 partially attenuated the cell apoptosis and the decrease in cell viability induced by AOPPs.

GLP-1 plays its protective role mainly by regulating RAGE-mediated NADPH oxidase activity and ROS generation. Intracellular ROS generation was measured using the fluorescent probe, DHE. Intracellular DHE is oxidized to ethidium, which binds DNA and stains nuclei bright fluorescent red. The level of oxidative stress was evaluated by the fluorescent intensity of DHE in the IMECs. GLP-1 markedly abrogated the AOPP-mediated ROS generation in the IMECs (Fig. 5A and B). We also examined the effect of GLP-1 on NADPH oxidase activity by measuring NADPH-dependent superoxide production. $\mathrm{O}_{2}^{-}$production derived from NADPH was significantly enhanced in the AOPP-exposed IMECs (Fig. 5C). However, following co-incubation with GLP-1, NADPH oxidase activity was significantly decreased $(\mathrm{p}<0.05)$. As it is well known that the intracellular effects of AOPPs are mediated by RAGE, we further investigated the effect of GLP-1 on the expression of RAGE in the AOPP-exposed cells. The expression of RAGE increased significantly in the IMECs cultured with the AOPPs, and the addition of GLP-1 to the AOPP culture medium counter- acted the AOPP-induced increase in RAGE expression (Fig. 5D). These data demonstrate that GLP-1 exerts a protective effect against AOPP-induced cell damage by downregulating RAGE expression and inhibiting the activity of NADPH oxidase.

\section{Discussion}

Increased recognition of vascular endothelial cell dysfunction as a link between diabetes and its vascular complications has highlighted the importance of determining the mechanisms underlying the pathophysiological abnormalities in microvascular endothelial cells and the development of diabetes $(17,29)$. Pancreatic microvascular endothelial dysfunction and subsequent islet ischemia may be the main cause of the initial dysfunction and the apoptosis of $\beta$-cells in type 2 diabetes. AOPPs, a typical representation of oxidized protein compounds, are not only considered to produce ROS, but are also known as pro-inflammatory and pro-oxidative compounds that may play a major role in increasing the prevalence of endothelial dysfunction (30-32).

However, whether and how AOPPs affect the survival of IMECs remains unknown. In this in vitro study, the results revealed that a higher apoptotic rate of cultured IMECs, as well as increased ROS production, were induced by expo- 

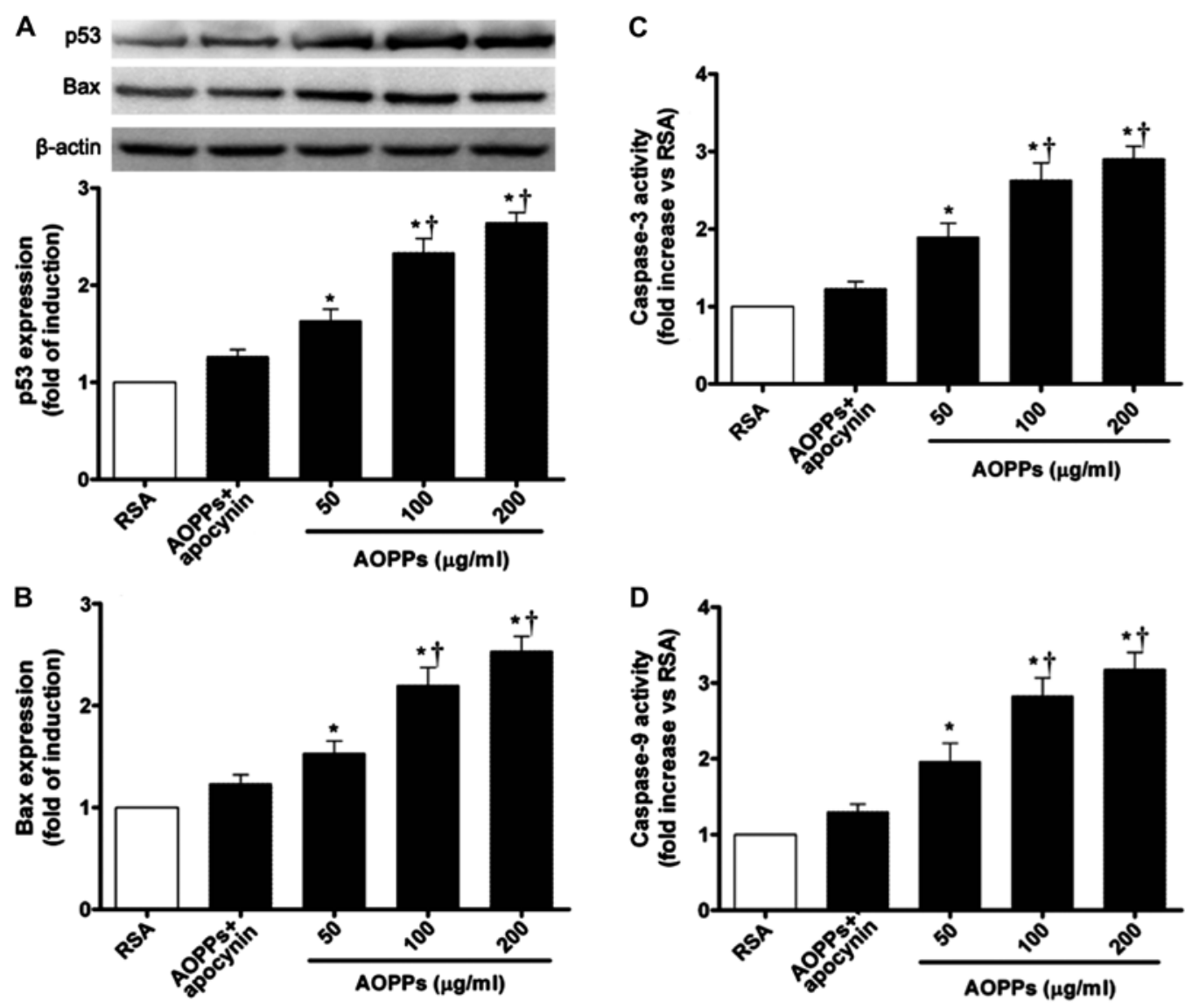

Figure 3. Advanced oxidation protein products (AOPPs) increase p53 and Bax protein expression, and caspase-3 and caspase-9 activity in cultured IMECs (A and B) The abundance of $\mathrm{p} 53$ and Bax in IMECs incubated with or without AOPPs was determined by western blot analysis. AOPP challenge increased p53 and Bax expression in cultured IMECs in a dose-dependent manner. (C and D) Caspase-3 and caspase-9 activity was measured using caspase-3 and caspase-9 activity assay kits. AOPP challenge signifcantly enhanced the activity of caspase- 3 and caspase- -9 . All values are the means \pm SD from at least 3 independent experiments. " $\mathrm{p}<0.05$ compared with the rat serum albumin (RSA) and AOPPs + apocynin group; ${ }^{\dagger} \mathrm{p}<0.05$ compared with the AOPP (50 $\left.\mu \mathrm{g} / \mathrm{ml}\right)$-exposed cells.
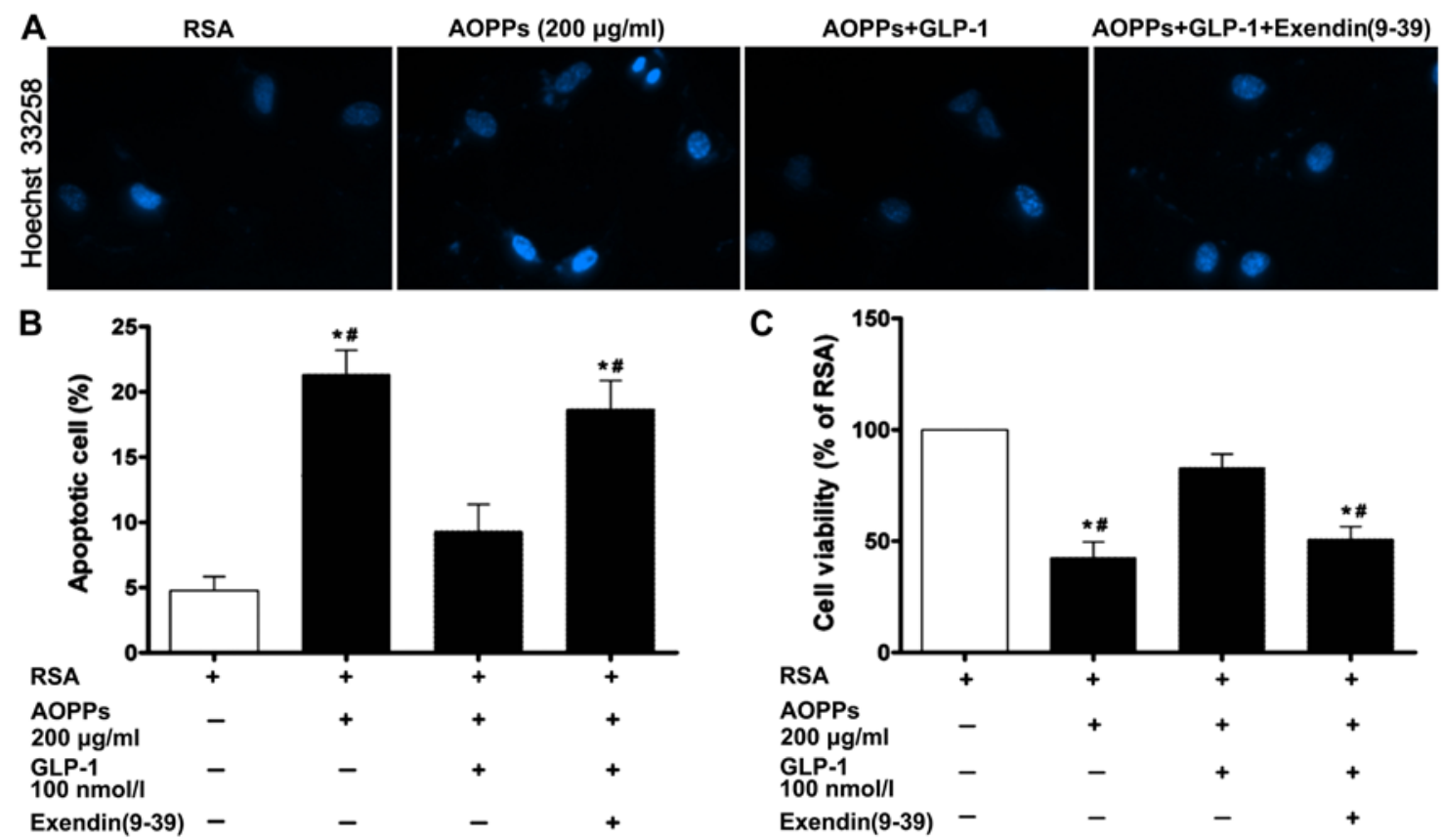

Figure 4. Glucagon-like peptide-1 (GLP-1) decreases the cell apoptosis and increases the viability of IMECs induced by advanced oxidation protein products (AOPPs). (A) Representative photographs labeling of Hoechst 33258 (blue) in IMECs exposed to AOPPs (200 $\mu \mathrm{g} / \mathrm{ml})$ in the prensece or absence of GLP-1 (100 nmol/l) for 48 h. (B) Apoptosis of rat IMECs induced by AOPPs and treated with GLP-1 (100 nmol/l) was determined with Annexin V-FITC/propidium iodide (PI) double staining and analyzed by flow cytometry. (C) The effect of GLP-1 on the viability of IMECs exposed to AOPPs was measured by cell counting kit- 8 assay. Data are expressed as the means $\pm \mathrm{SD}$. " $\mathrm{p}<0.05$ compared with the rat serum albumin (RSA) group; ${ }^{*} \mathrm{p}<0.05$ compared with the AOPP + GLP-1 group. Exendin(9-39), an antagonist for receptor of GLP-1 (GLP-1R). 


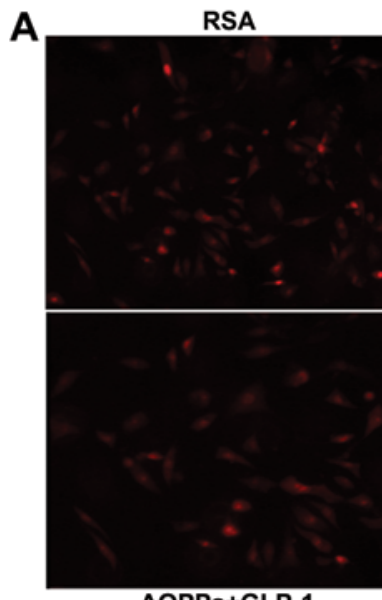

AOPPs+GLP-1

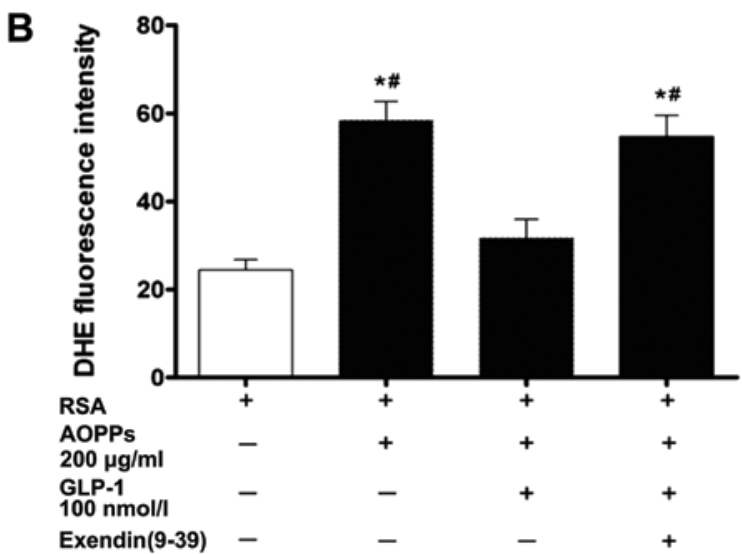

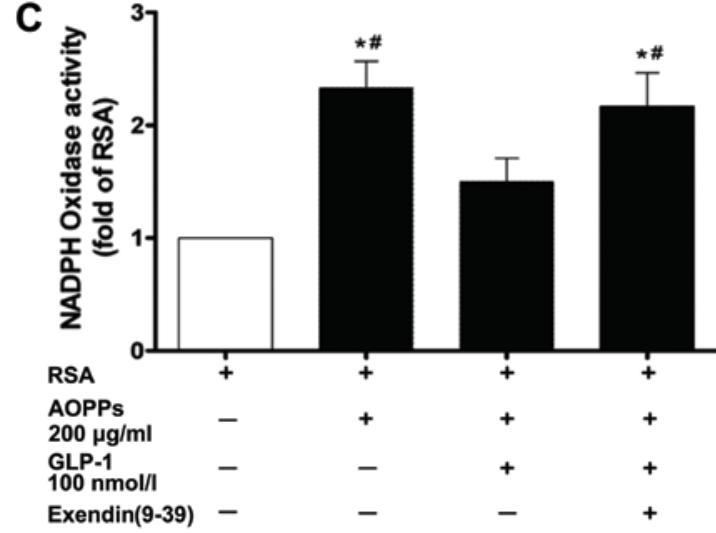
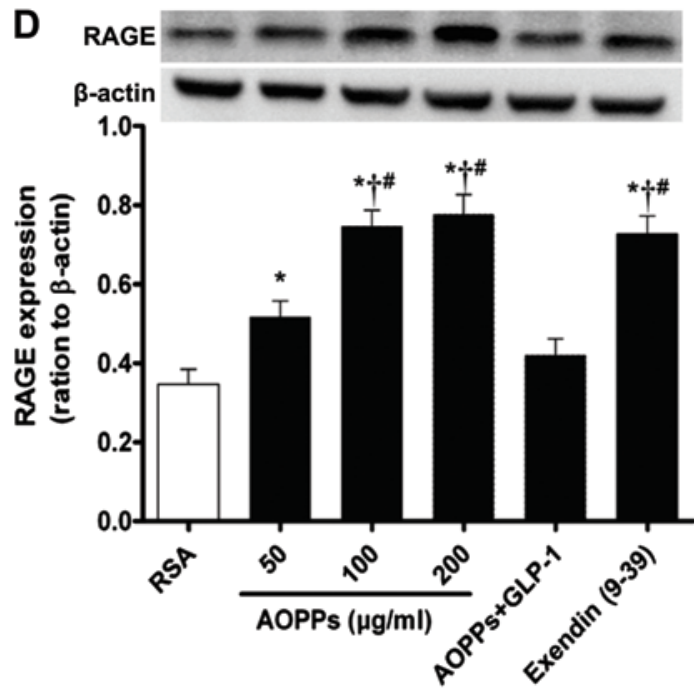

Figure 5. Effect of glucagon-like peptide-1 (GLP-1) on intracellular reactive oxygen species (ROS) level, NADPH oxidase activity and expression of receptor for advanced glycation end products (RAGE) in IMECs exposed to advanced oxidation protein products (AOPPs). (A) Dihydroethidium (DHE) fluorescence imaging of ROS in IMECs exposed to AOPPs $(200 \mu \mathrm{g} / \mathrm{ml})$ in the prensece or absence of GLP-1 (100 nmol/1) for $48 \mathrm{~h}$. (B) Fluorescence intensity was measured by flow cytometry. Treatment with GLP-1 (100 nmol/1) decreased the ROS level significantly compared with the cells exposed to AOPP (not treated with GLP-1) or those treated with or rat serum albumin (RSA). (C) Membrane NADPH oxidase activity induced by AOPPs was markedly inhibited in the presence of GLP-1 (100 nmol/1). (D) The effect of GLP-1 on the expression of RAGE in IMECs induced by various concentrations of AOPPs was determinated by western blot analysis. Exendin(9-39) refers to RSA + AOPPs + GLP-1 + Exendin(9-39). Data are expressed as the means \pm SD of 3 independent experiments. * $<<0.05$ compared with the RSA-treated group; ${ }^{\dagger} \mathrm{p}<0.05$ compared with AOPPs $(50 \mu \mathrm{g} / \mathrm{ml})$-exposed group; ${ }^{\#} \mathrm{p}<0.05$ compared with the GLP-1 + AOPPs group.

sure to AOPPs in a dose-dependent manner. Increasing the concentration of AOPPs also had a significant effect on IMEC cell viability; a significant decrease in viability was observed in cells incubated with various concentrations of AOPPs compared with those exposed to native RSA.

We then sought to uncover the mechanism underlying the induction of apoptosis by AOPPs in IMECs. AOPPs, as well as AGEs, signal via RAGE and induce endothelial dysfunction. Early studies have demonstrated that AOPPs stimulate ROS generation from a variety of cells through a mechanism that involves NADPH oxidases $(10,12)$. AOPPs have been shown to induce inflammatory responses and insulin resistance in cultured adipocytes via the induction of endoplasmic reticulum stress mediated by ROS, which were generated by the activation of NADPH oxidase (11). Zhou et al demonstrated that AOPPs co-localized and interacted with the receptor of AGEs on podocytes; increasing the amount of AOPPs in the medium rapidly triggered the generation of intracellular superoxide by the activation of NADPH oxidase, and in turn resulted in the upregulation of p53, Bax, caspase-3 activity and apoptosis. Blocking or silencing RAGE significantly protected podocytes from AOPP-induced apoptosis both in vitro and in vivo $(9,33)$.

In the present study, our data indicated that: i) AOPPs induced NADPH oxidase-dependent ROS production in IMECs; ii) NADPH oxidase activity was significantly enhanced in AOPP-exposed IMECs; iii) the expression levels of $\mathrm{p} 47^{\text {phox }}$ and $\mathrm{p} 22^{\text {phox }}$, the essential subunits of NADPH oxidase in IMECs, were significantly upregulated following exposure to AOPPs. It was interesting that AOPP-triggered NADPH oxidase-dependent ROS production was almost completely blocked by treatment with the NADPH oxidase inhibitor, apocynin. We further found that AOPPs not only increased RAGE expression in cultured IMECs in a dose-dependent manner, but also increased the abundance of p53 and Bax protein expression. The activity of caspase- 3 and caspase- 9 was simultaneously significantly enhanced in the cells treated with AOPPs. All these results demonstrated that the AOPPinduced apoptosis of IMECs is mainly associated with the increased activity of caspase- 3 and caspase- 9 involved in the 
RAGE-mediated p53/Bax pathway, which is consistent with the findings of previous studies $(9,33)$.

GLP-1 and its long-acting peptide analog, exendin-4, both well-known prospective therapeutic candidates, have pleiotropic effects that include the enhancement of glucosedependent insulin release, as well as $\beta$-cell proliferation and survival $(34,35)$. In addition to its important role in regulating glucose homeostasis, GLP-1 has also been suggested to exert beneficial effects on the cardiovascular system, such as improvements in blood pressure, vascular tone and myocardial function (20). However, it is not clear whether GLP-1 can ameliorate the detrimental effects of AOPPs on IMECs.

In this study, we demonstrated in vitro that treatment with GLP-1 significantly decreased AOPP-induced apoptosis, as well as ROS generation in the IMECs, and markedly improved cell viability. We then investigated the potential mechanism through which GLP-1 exerts its protective effects on IMECs, and we found that RAGE expression in the IMECs, which was induced by AOPPs, was decreased in the presence of GLP-1. Of note, NADPH oxidase activity measured by NADPH oxidase-dependent superoxide production was also markedly inhibited by the intervention of GLP-1. This protective effect of GLP-1 on IMECs was inhibited by treatment with exendin(9-39), an antagonist of GLP-1R.

During the past decade, a growing body of evidence has shown that the addition of GLP-1 can protect $\beta$-cells from the detrimental effects of AGEs by downregulating AGE-induced RAGE expression (21). Co-incubation with GLP-1 has been shown to reverse the glycated serum-mediated detrimental effects by decreasing oxidative stress and triggering protective intercellular pathways in human umbilical vein endothelial cells (HUVECs) and HIT-T15 cells (36,37). GLP-1 intervention prevented the AGE-induced impairement in viability in many cell types; this important effect was related to the reduction of oxidative stress and alterations in Bcl-2- and caspase-mediated pathways (38-40). Our results are in accordance with those of previous studies $(36,37,40)$ and demonstrate that GLP-1 mainly plays a protective role via RAGE-mediated NADPH oxidase activity.

In conclusion, in this study, we provide insight into the pathological processes which may take place within pancreatic microvascular endothelial cells as a result of AOPP-induced cytotoxicity. By virtue of their participation in pancreatic $\beta$-cell development and pathophysiology, IMECs have been regarded as a target and an effector for the damage induced by AOPPs, finally contributing to progressive islet dysfunction. Treatment with GLP-1 not only targets the accumulation of AOPPs, but may also attenuate the progression of diabetes and diabetes-related complications.

\section{Acknowledgements}

This study was supported by the Guangdong Provincial Key Laboratory of Malignant Tumor Epigenetics and Gene Regulation, the Sun Yat-Sen Memorial Hospital, the Sun Yat-Sen University. This study was supported by a grant from the National Natural Science Foundation of China (no. 81500623) and the special funds for public welfare research and capacity building in Guangdong province (no. 2014A020212489).

\section{References}

1. Son SM: Role of vascular reactive oxygen species in development of vascular abnormalities in diabetes. Diabetes Res Clin Pract 77 (Suppl 1): S65-S70, 2007.

2. Maejima Y, Kuroda J, Matsushima S, Ago T and Sadoshima J: Regulation of myocardial growth and death by NADPH oxidase. J Mol Cell Cardiol 50: 408-416, 2011.

3. Giacco F and Brownlee M: Oxidative stress and diabetic complications. Circ Res 107: 1058-1070, 2010.

4. Witko-Sarsat V, Friedlander M, Capeillère-Blandin C Nguyen-Khoa T, Nguyen AT, Zingraff J, Jungers P and Descamps-Latscha B: Advanced oxidation protein products as a novel marker of oxidative stress in uremia. Kidney Int 49: 1304-1313, 1996.

5. Krzystek-Korpacka M, Patryn E, Boehm D, Berdowska I, Zielinski B and Noczynska A: Advanced oxidation protein products (AOPPs) in juvenile overweight and obesity prior to and following weight reduction. Clin Biochem 41: 943-949, 2008.

6. Sakul A, Cumaoğlu A, Aydin E, Ari N, Dilsiz N and Karasu C: Age- and diabetes-induced regulation of oxidative protein modification in rat brain and peripheral tissues: Consequences of treatment with antioxidant pyridoindole. Exp Gerontol 48: 476-484, 2013.

7. Martín-Gallán P, Carrascosa A, Gussinyé M and Domínguez C: Biomarkers of diabetes-associated oxidative stress and antioxidant status in young diabetic patients with or without subclinical complications. Free Radic Biol Med 34: 1563-1574, 2003.

8. Atabek ME, Keskin M, Yazici C, Kendirci M, Hatipoglu N, Koklu E and Kurtoglu S: Protein oxidation in obesity and insulin resistance. Eur J Pediatr 165: 753-756, 2006.

9. Zhou LL, Cao W, Xie C, Tian J, Zhou Z, Zhou Q, Zhu P, Li A, Liu Y, Miyata T, et al: The receptor of advanced glycation end products plays a central role in advanced oxidation protein products-induced podocyte apoptosis. Kidney Int 82: 759-770, 2012.

10. Wei XF, Zhou QG, Hou FF, Liu BY and Liang M: Advanced oxidation protein products induce mesangial cell perturbation through PKC-dependent activation of NADPH oxidase. Am J Physiol Renal Physiol 296: F427-F437, 2009.

11. Zhou QG, Zhou M, Lou AJ, Xie D and Hou FF: Advanced oxidation protein products induce inflammatory response and insulin resistance in cultured adipocytes via induction of endoplasmic reticulum stress. Cell Physiol Biochem 26: 775-786, 2010.

12. Li HY, Hou FF, Zhang X, Chen PY, Liu SX, Feng JX, Liu ZQ, Shan YX, Wang GB, Zhou ZM, et al: Advanced oxidation protein products accelerate renal fibrosis in a remnant kidney model. J Am Soc Nephrol 18: 528-538, 2007.

13. Shi XY, Hou FF, Niu HX, Wang GB, Xie D, Guo ZJ, Zhou ZM, Yang F, Tian JW and Zhang X: Advanced oxidation protein products promote inflammation in diabetic kidney through activation of renal nicotinamide adenine dinucleotide phosphate oxidase. Endocrinology 149: 1829-1839, 2008.

14. Liu SX, Hou FF, Guo ZJ, Nagai R, Zhang WR, Liu ZQ, Zhou ZM, Zhou M, Xie D, Wang GB and Zhang X: Advanced oxidation protein products accelerate atherosclerosis through promoting oxidative stress and inflammation. Arterioscler Thromb Vasc Biol 26: 1156-1162, 2006.

15. Chen S, Liu L, Sun X, Liu Y and Song T: Captopril restores endothelium-dependent relaxation induced by advanced oxidation protein products in rat aorta. J Cardiovasc Pharmacol 46: 803-809, 2005.

16. Guo ZJ, Niu HX, Hou FF, Zhang L, Fu N, Nagai R, Lu X, Chen BH, Shan YX, Tian JW, et al: Advanced oxidation protein products activate vascular endothelial cells via a RAGE-mediated signaling pathway. Antioxid Redox Signal 10: 1699-1712, 2008.

17. Tal MG: Type 2 diabetes: Microvascular ischemia of pancreatic islets? Med Hypotheses 73: 357-358, 2009.

18. Zanone MM, Favaro E and Camussi G: From endothelial to beta cells: Insights into pancreatic islet microendothelium. Curr Diabetes Rev 4: 1-9, 2008.

19. Baggio LL and Drucker DJ: Biology of incretins: GLP-1 and GIP. Gastroenterology 132: 2131-2157, 2007.

20. Abu-Hamdah R, Rabiee A, Meneilly GS, Shannon RP, Andersen DK and Elahi D: Clinical review: The extrapancreatic effects of glucagon-like peptide- 1 and related peptides. J Clin Endocrinol Metab 94: 1843-1852, 2009. 
21. Puddu A, Storace D, Durante A, Odetti P and Viviani GL: Glucagon-like peptide-1 counteracts the detrimental effects of advanced glycation end-products in the pancreatic beta cell line HIT-T 15. Biochem Biophys Res Commun 398: 462-466, 2010.

22. Ishibashi Y, Nishino Y, Matsui T, Takeuchi M and Yamagishi S: Glucagon-like peptide-1 suppresses advanced glycation end product-induced monocyte chemoattractant protein-1 expression in mesangial cells by reducing advanced glycation end product receptor level. Metabolism 60: 1271-1277, 2011.

23. Ishibashi Y, Matsui T, Takeuchi M and Yamagishi S: Sitagliptin augments protective effects of GLP-1 against advanced glycation end product receptor axis in endothelial cells. Horm Metab Res 43: 731-734, 2011.

24. Capeillere-Blandin C, Gausson V, Descamps-Latscha B and Witko-Sarsat V: Biochemical and spectrophotometric significance of advanced oxidized protein products. Biochim Biophys Acta 1689: 91-102, 2004.

25. Arbet-Engels C, Darquy S, Capron F and Reach G: Isolation of islets of Langerhans from the rat and pig pancreas using a modified UW solution from organ storage to islet purification. Diabete Metab 19: 590-596, 1993

26. Lou J, Triponez F, Oberholzer J, Wang H, Yu D, Buhler L, Cretin N, Mentha G, Wollheim CB and Morel P: Expression of alpha-1 proteinase inhibitor in human islet microvascular endothelial cells. Diabetes 48: 1773-1778, 1999.

27. Li JM, Mullen AM, Yun S, Wientjes F, Brouns GY, Thrasher AJ and Shah AM: Essential role of the NADPH oxidase subunit p47(phox) in endothelial cell superoxide production in response to phorbol ester and tumor necrosis factor-alpha. Circ Res 90 143-150, 2002.

28. Zheng S, Zhong ZM, Qin S, Chen GX, Wu Q, Zeng JH, Ye WB, $\mathrm{Li} W$, Yuan K, Yao L, et al: Advanced oxidation protein products induce inflammatory response in fibroblast-like synoviocytes through NADPH oxidase -dependent activation of NF- $\kappa$ B. Cell Physiol Biochem 32: 972-985, 2013.

29. Garcia Soriano F, Virág L, Jagtap P, Szabó E, Mabley JG, Liaudet L, Marton A, Hoyt DG, Murthy KG, Salzman AL, et al: Diabetic endothelial dysfunction: The role of poly(ADP-ribose) polymerase activation. Nat Med 7: 108-113, 2001

30. Barsotti A, Fabbi P, Fedele M, Garibaldi S, Balbi M, Bezante GP, Risso D, Indiveri F, Ghigliotti $G$ and Brunelli C: Role of advanced oxidation protein products and Thiol ratio in patients with acute coronary syndromes. Clin Biochem 44: 605-611, 2011.
31. Simm A, Wagner J, Gursinsky T, Nass N, Friedrich I, Schinzel R, Czeslik E, Silber RE and Scheubel RJ: Advanced glycation endproducts: A biomarker for age as an outcome predictor after cardiac surgery? Exp Gerontol 42: 668-675, 2007.

32. Gradinaru D, Borsa C, Ionescu C and Margina D: Advanced oxidative and glycoxidative protein damage markers in the elderly with type 2 diabetes. J Proteomics 92: 313-322, 2013.

33. Zhou LL, Hou FF, Wang GB, Yang F, Xie D, Wang YP and Tian JW: Accumulation of advanced oxidation protein products induces podocyte apoptosis and deletion through NADPH-dependent mechanisms. Kidney Int 76: 1148-1160, 2009.

34. Tschen SI, Dhawan S, Gurlo T and Bhushan A: Age-dependent decline in beta-cell proliferation restricts the capacity of beta-cell regeneration in mice. Diabetes 58: 1312-1320, 2009.

35. Kim W and Egan JM: The role of incretins in glucose homeostasis and diabetes treatment. Pharmacol Rev 60: 470-512, 2008.

36. Ishibashi $Y$, Matsui $T$, Takeuchi $M$ and Yamagishi S: Glucagon-like peptide-1 (GLP-1) inhibits advanced glycation end product (AGE)-induced up-regulation of VCAM-1 mRNA levels in endothelial cells by suppressing AGE receptor (RAGE) expression. Biochem Biophys Res Commun 391: 1405-1408, 2010.

37. Puddu A, Sanguineti R, Durante A, Nencioni A, Mach F, Montecucco F and Viviani GL: Glucagon-like peptide-1 triggers protective pathways in pancreatic beta-cells exposed to glycated serum. Mediators Inflamm 2013: 317120, 2013.

38. Luciano Viviani G, Puddu A, Sacchi G, Garuti A, Storace D, Durante A, Monacelli F and Odetti P: Glycated fetal calf serum affects the viability of an insulin-secreting cell line in vitro. Metabolism 57: 163-169, 2008.

39. Matsui T, Nishino Y, Takeuchi M and Yamagishi S: Vildagliptin blocks vascular injury in thoracic aorta of diabetic rats by suppressing advanced glycation end product-receptor axis. Pharmacol Res 63: 383-388, 2011.

40. Zhan Y, Sun HL, Chen H, Zhang H, Sun J, Zhang Z and Cai DH: Glucagon-like peptide-1 (GLP-1) protects vascular endothelial cells against advanced glycation end products (AGEs)-induced apoptosis. Med Sci Monit 18: BR286-BR291, 2012. 